ГЕМОРРАГИЧЕСКАЯ БЕЗОПАСНОСТЬ ПРИМЕНЕНИЯ

ТИКАГРЕЛОРА У БОЛЬНЫХ ОСТРЫМ КОРОНАРНЫМ

СИНДРОМОМ С ПОДЪЕМОМ СЕГМЕНТА SТ, ПОЛУЧИВШИХ

ТРОМБОЛИТИЧЕСКУЮ ТЕРАПИЮ В ПОВСЕДНЕВНОЙ

КЛИНИЧЕСКОЙ ПРАКТИКЕ: 30-ДНЕВНЫЕ РЕЗУЛЬТАТЫ

НАБЛЮДЕНИЙ

\author{
А.В. Бочаров, Д.В. Сидоров \\ Костромская областная клиническая больница имени Королева Е.И., Кострома, Российская Федерация
}

Обоснование. Эффективная антитромботическая терапия является необходимым условием сохранения проходимости инфарктзависимой коронарной артерии при проведении первичного чрескожного коронарного вмешательства. Цель - сравнить безопасность применения тикагрелора у больных острым коронарным синдромом с подъемом сегмента ST после неэффективной тромболитической терапии и успешно выполненной реканализации инфарктзависимой артерии методом чрескожного коронарного вмешательства, которым нагрузочная доза тикагрелора назначалась в интервале времени от выполнения тромболитической терапии до начала выполнения чрескожного коронарного вмешательства, в сравнении с результатами исследований TREAT по риску возникновения кровотечений в условиях реальной клинической практики. Методы. Выполнен сравнительный анализ результатов 30-дневного наблюдения 52 пациентов с острым коронарным синдромом с подъемом сегмента ST, получивших тромболитическую терапию и раннее назначение тикагрелора с группой тикагрелора по данным исследования TREAT по параметрам геморрагической безопасности. Результаты. В основной группе исследования достоверно чаще встречались артериальная гипертензия, дислипидемия, генерализованный атеросклероз, хроническая обструктивная болезнь легких и перенесенный инфаркт миокарда в анамнезе. Анализ результатов не выявил достоверных различий между группами по частоте и рискам возникновения геморрагических осложнений ( $(=0,85)$. Заключение. Достоверные различия в частоте крупных кровотечений по критериям TIMI и BARC между группами отсутствуют, что свидетельствует о безопасности раннего (в пределах 24 ч после выполнения тромболизиса применения тикагрелора при фармакоинвазивном подходе в условиях реальной клинической практики.

Ключевые слова: острый коронарный синдром, тикагрелор, тромболитическая терапия, кровотечения, безопасность.

(Для цитирования: Бочаров А.В., Сидоров Д.В. Геморрагическая безопасность применения тикагрелора у больных острым коронарным синдромом с подъемом сегмента ST, получивших тромболитическую терапию в повседневной клинической практике: 30-дневные результаты наблюдений. Клиническая практика. 2020;11(1):67-72. doi: 10.17816/clinpract19125)

\title{
TICAGRELOR HEMORRHAGIC SAFETY IN PATIENTS WITH ACUTE CORONARY SYNDROME WITH ST-SEGMENT ELEVATION RECEIVED THROMBOLYTIC THERAPY IN DAILY CLINICAL PRACTICE: 30-DAY OBSERVATION RESULTS
}

\author{
A.V. Bocharov, D.V. Sidorov \\ Kostroma Regional Clinical Hospital Named After Korolev E.I., Kostroma, Russian Federation
}

Background. Effective antithrombotic therapy is a necessary condition for maintaining the patency of the infarct-dependent coronary artery during a primary percutaneous coronary intervention. Aim. To compare the safety of ticagrelor use in patients with STEMI after ineffective thrombolytic treatment (TLT) and successfully performed recanalization of infarct-dependent artery (IDA) by PCI, withticagrelor load- 
ing dose administered in the time window from TLT to PCI, in comparison with the TREAT study results on the risk of bleeding in the real clinical practice. Methods. A comparative analysis of the results of a 30-day follow-up of 52 patients with acute coronary syndrome with ST-segment elevation who received a thrombolytic therapy with alteplasa and early ticagrelor administration with the ticagrelor group in the TREAT study on the parameters of hemorrhagic safety. Results. Arterial hypertension, dyslipidemia, generalized atherosclerosis, chronic obstructive pulmonary disease and a history of myocardial infarction were significantly more common in the study group. The analysis of the results revealed no significant differences between the groups in the frequency and risk of hemorrhagic complications. Conclusion. There are no significant differences in the frequency of major bleeding according to the TIMI and BARC criteria between the groups, which indicates the safety of early (within 24 hours after thrombolysis) ticagrelor use in the pharmacoinvasive approach in the real clinical practice.

Keywords: acute coronary syndrome, ticagrelor, thrombolytic therapy, bleeding, safety.

(For citation: Bocharov AV, Sidorov DV. Ticagrelor Hemorrhagic Safety in Patients with Acute Coronary Syndrome with ST-Segment Elevation Received Thrombolytic Therapy in Daily Clinical Practice: 30-Day Observation Results. Journal of Clinical Practice. 2020;11(1):67-72. doi: 10.17816/clinpract19125)

\section{ОБОСНОВАНИЕ}

Современные рекомендации по ведению больных острым коронарным синдромом с подъемом сегмента ST в качестве оптимального метода реперфузии рассматривают первичное чрескожное коронарное вмешательство [1]. В случае невозможности своевременного выполнения интервенционного вмешательства (не позднее 120 мин от первого медицинского контакта) рекомендуется применять фармакоинвазивный подход, включающий выполнение жизнеспасающей системной тромболитической терапии, которая должна быть проведена не позднее 10 мин от момента снятия электрокардиограммы. Успешность фармакоинвазивного подхода подтверждена результатами исследования STREAM (STrategic Reperfusion Early After Myocardial infarction): суммарная частота смертельных исходов, случаев кардиогенного шока, застойной сердечной недостаточности или повторного инфаркта миокарда в течение первых 30 дней была ниже в группе пациентов, которым выполнялась тромболитическая терапия на догоспитальном этапе и затем эндоваскулярное вмешательство на коронарных артериях [2]. В обеих группах при наблюдении до 1 года отмечены сходная общая смертность и смертность от сердечно-сосудистых причин. В условиях реальной клинической практики и географических особенностей территорий субъектов Российской Федерации доступность первичного чрескожного коронарного вмешательства может быть сильно ограничена. Например, площадь Костромской области составляет 60,2 тыс. км², расстояние от города Мантурово до Регионального сосудистого центра, где возможно выполнение чрескожного коронарного вмешательства, составляет 230 км, от города Шарьи - 278 км. В условиях значительной отдаленности от центра оказания высокотехнологичной медицинской помощи многих населенных пунктов Костромской области проведение первичного чрескожного коронарного вмешательства в пределах 120 мин от первого медицинского контакта во многих случаях становится невозможным, поэтому фармакоинвазивный подход для отдаленных населенных пунктов является приоритетным.

Эффективная антитромботическая терапия является необходимым условием сохранения проходимости инфарктзависимой коронарной артерии при проведении первичного чрескожного коронарного вмешательства. При этом вопросы безопасности такого лечения становятся особенно актуальными. Данной проблеме было посвящено международное исследование TREAT (administration of TicagRElor in pAtients with ST elevation myocardial infarction treated with pharmacological Thrombolysis) $[3,4]$, доказавшее сопоставимость терапии тикагрелором на уровне первичной конечной точки исследования по сравнению с терапией клопидогрелом у пациентов с острым коронарным синдромом с подъемом сегмента ST, получивших тромболитическую терапию, по частоте развития «больших» сердечно-сосудистых событий (рецидив инфаркта миокарда, сердечно-сосудистая смерть, острое нарушение мозгового кровообращения). Это же исследование доказало, что при использовании тикагрелора отсутствуют достоверные различия по частоте развития фатальных и внутричерепных кровотечений согласно критериям TIMI 
(Thrombolysis In Myocardial Infarction) [5] и BARC (Bleeding Academic Research Consortium) [6].

Цель исследования - сравнить геморрагическую безопасность применения тикагрелора у больных острым коронарным синдромом с подъемом сегмента ST после неэффективной тромболитической терапии и успешно выполненной реканализации инфарктзависимой артерии методом чрескожного коронарного вмешательства, которым нагрузочная доза тикагрелора назначалась в интервале времени от выполнения тромболитической терапии до начала чрескожного коронарного вмешательства, в сравнении с результатами исследования TREAT по риску возникновения кровотечений в условиях реальной клинической практики.

\section{МЕТОДЫ}

\section{Дизайн исследования}

Выполнен сравнительный анализ результатов геморрагической безопасности 30-дневного наблюдения за пациентами с острым коронарным синдромом с подъемом сегмента ST, получившими тромболитическую терапию препаратом альтеплаза (Актилизе) и раннее назначение тикагрелора с группой тикагрелора в исследовании TREAT [3].

\section{Критерии соответствия}

Критериями включения являлись пациенты с рецидивирующей ишемией миокарда, нестабильностью гемодинамики, отсутствием снижения подъема сегмента ST электрокардиограммы более чем на 50\% через 60-90 мин от момента окончания тромболитической терапии.

Критериями исключения - возраст менее 18 и более 75 лет; отсутствие приверженности к лекарственной терапии; противопоказания к приему дезагрегантов; наличие заболеваний, лимитирующих выживаемость; онкологические заболевания; хроническая почечная недостаточность; фракция выброса левого желудочка менее $30 \%$.

Критерии невключения: больные, получившие согласно протоколу исследования тромболитическую терапию в течение 24 ч до рандомизации.

\section{Условия проведения}

Исследование выполнено на базе ОГБУЗ «Костромская областная клиническая больница имени Королева Е.И.» в период с 2014 по 2019 г. От всех пациентов было получено согласие на обра- ботку персональных данных и медицинские вмешательства.

\section{Продолжительность исследования}

Наблюдение после выполнения чрескожного коронарного вмешательства осуществлялось на госпитальном и амбулаторном этапах на протяжении 30 дней.

\section{Исходы исследования}

\section{Основной исход исследования}

Конечными точками наблюдения являлись любые учитываемые кровотечения по шкалам TIMI [2] и/или BARC [3].

\section{Этическая экспертиза}

Проведенное исследование соответствует стандартам Хельсинкской декларации (Declaration Helsinki). Согласно законодательству Российской Федерации, одобрения Локального этического комитета не требовалось.

\section{Статистический анализ}

\section{Принципы расчета размера выборки}

Данное исследование является сплошным нерандомизированным исследованием, что теоретически могло отразиться на полученных результатах. При расчете объема выборки для возможности сравнения с исследованием TREAT с доверительной вероятностью 95\% и доверительным интервалом погрешности $\pm 5 \%$ с поправкой для малых генеральных совокупностей минимальная репрезентативная выборка равнялась 44.

\section{Методы статистического анализа данных}

Статистическую обработку проводили при помощи программы Statistica версии 13.3 (TIBCO Software Inc., 2017; http://statistica.io). Результаты представлены медианой с интерквартильным размахом в виде $25 \%$ и $75 \%$ перцентилей при асимметричном распределении. Тип распределения количественных переменных оценивали по критерию Колмогорова-Смирнова с поправкой Лиллиефорса. При сравнении количественных данных применяли U-критерий Манна-Уитни с поправкой непрерывности. Для сопоставления качественных переменных использовали Хи-квадрат с поправкой Йейтса. Отношение шансов (odds ratio) развития неблагоприятных событий рассчитывали по четырехпольным таблицам. Достоверными различия между группами считались при $p<0,05$. 


\section{РЕЗУЛЬТАТЫ}

\section{Основные результаты исследования}

В основной группе исследования достоверно чаще встречались артериальная гипертензия, дислипидемия, генерализованный атеросклероз, хроническая обструктивная болезнь легких и перенесенный инфаркт миокарда в анамнезе (табл. 1).

Анализ результатов не выявил достоверных различий между группами по частоте и рискам возникновения геморрагических осложнений (табл. 2, рис. 1).

Таблица 1

\section{Клиническая характеристика пациентов групп}

\begin{tabular}{|c|c|c|c|}
\hline Показатель & $\begin{array}{c}\text { Группа КОКБ } \\
(n=52)\end{array}$ & $\begin{array}{c}\text { Группа тикагрелора } \\
\text { исследования TREAT [4] } \\
(n=1913)\end{array}$ & $p$ \\
\hline Возраст, лет & $59[52,8 ; 63,3]$ & $59[51,6 ; 65,2]$ & 0,49 \\
\hline Женский пол, \% (чел.) & $15,4(8)$ & $22,6(433)$ & 0,29 \\
\hline Индекс массы тела, кг/м² & $28,8[26 ; 30]$ & $26,5[24 ; 29,8]$ & 0,48 \\
\hline Артериальная гипертензия, \% (чел.) & $100(52)$ & 56 (1072) & 0 \\
\hline Дислипидемия, \% (чел.) & $98,1(51)$ & $27,4(524)$ & 0 \\
\hline Сахарный диабет, \% (чел.) & $23,1(12)$ & $17,4(332)$ & 0,4 \\
\hline Заболевания периферических артерий, \% (чел.) & $53,9(28)$ & $0,9(17)$ & 0 \\
\hline Фибрилляция предсердий, \% (чел.) & $0(0)$ & $1,1(21)$ & 0,94 \\
\hline Хроническая обструктивная болезнь легких, \% (чел.) & $9,6(5)$ & $2,6(50)$ & 0,01 \\
\hline Бронхиальная астма, \% (чел.) & $1,9(1)$ & $1,5(28)$ & 0,76 \\
\hline Курение, \% (чел.) & $51,9(27)$ & $46,1(881)$ & 0,56 \\
\hline Подагра, \% (чел.) & $1,9(1)$ & $2,0(39)$ & 0,67 \\
\hline Застойная сердечная недостаточность, \% (чел.) & $5,8(3)$ & $2,0(38)$ & 0,15 \\
\hline Перенесенный инфаркт миокарда в анамнезе, \% (чел.) & $21,2(11)$ & $9,3(178)$ & 0,01 \\
\hline $\begin{array}{l}\text { Острое нарушение мозгового кровообращения } \\
\text { в анамнезе, \% (чел.) }\end{array}$ & $0(0)$ & $4,3(83)$ & 0,21 \\
\hline $\begin{array}{l}\text { Чрескожное коронарное вмешательство } \\
\text { в анамнезе, \% (чел.) }\end{array}$ & $7,7(4)$ & $5,9(113)$ & 0,8 \\
\hline Коронарное шунтирование в анамнезе, \% (чел.) & $1,9(1)$ & $0,8(15)$ & 0,9 \\
\hline $\begin{array}{l}\text { Высокий класс острой сердечной недостаточности } \\
\text { (Killip class II, III, IV), \% (чел.) }\end{array}$ & $7,7(4)$ & $7,9(152)$ & 0,94 \\
\hline
\end{tabular}

Примечание. КОКБ - Костромская областная клиническая больница им. Королева Е.И.

Результаты исследования

\begin{tabular}{|c|c|c|c|}
\hline Показатель & $\begin{array}{c}\text { Группа КОКБ } \\
(n=52)\end{array}$ & $\begin{array}{c}\text { Группа тикагрелора } \\
\text { исследования TREAT [4] } \\
(n=1913) \\
\end{array}$ & $p$ \\
\hline \multicolumn{4}{|c|}{ Классификация кровотечений TIMI } \\
\hline Незначительные кровотечения, \% (чел.) & $3,9(2)$ & $2,5(47)$ & 0,97 \\
\hline Умеренные кровотечения, \% (чел.) & $0(0)$ & $3,2(61)$ & 0,37 \\
\hline Большие кровотечения, \% (чел.) & $1,9(1)$ & $0,7(14)$ & 0,87 \\
\hline \multicolumn{4}{|c|}{ Классификация кровотечений BARC } \\
\hline Тип 1 & $3,9(2)$ & $2,5(47)$ & 0,97 \\
\hline Тип 2 & $0(0)$ & $2,0(38)$ & 0,61 \\
\hline Тип 3-5 & $1,9(1)$ & $1,3(24)$ & 0,87 \\
\hline Внутричерепные кровотечения, \% (чел.) & $0(0)$ & $0,4(8)$ & 0,53 \\
\hline Смертельные кровотечения, \% (чел.) & $0(0)$ & $0,2(3)$ & 0,13 \\
\hline Все кровотечения, \% (чел.) & $5,8(3)$ & $5,4(103)$ & 0,85 \\
\hline
\end{tabular}

Примечание. КОКБ - Костромская областная клиническая больница им. Королева Е.И. 
Рис. 1. Оценка отношения шансов риска возникновения геморрагических осложнений в группах

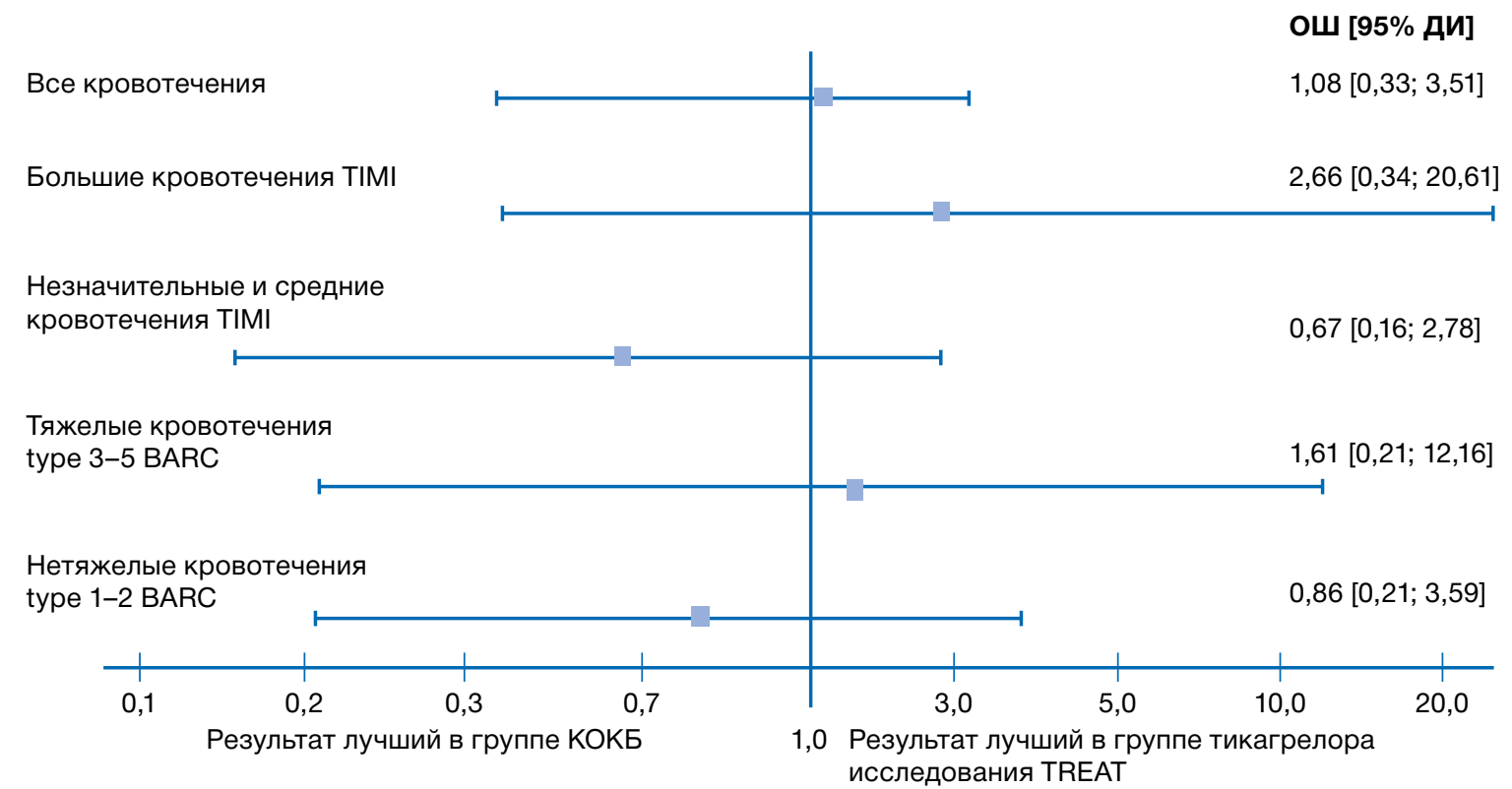

Примечание. ОШ - отношение шансов, 95\% дИ - 95\% доверительный интервал.

\section{ОБСУЖДЕНИЕ}

Двойная антитромбоцитарная терапия с сочетанием аспирина и клопидогрела используется для поддержки реперфузии при тромболитической терапии на основании результатов исследований CLARITI-TIMI 28 и COMMIT-CCS2 [7, 8]. Возможность успешной замены клопидогрела на более мощный блокатор Р2Y12 рецепторов тромбоцитов тикагрелор у широкого спектра больных острым коронарным синдромом показана в исследовании PLATO (PLATelet Inhibition and Clinical Outcomes) [9]. Доказано, что его назначение в пределах 24 ч от начала симптомов острого коронарного синдрома снижает достоверно суммарный риск неблагоприятных ишемических событий (инфаркта миокарда, острого нарушения мозгового кровообращения или смерти от сердечно-сосудистых причин) и сопровождается снижением летальности от всех причин за 12 мес наблюдений [9].

Применение тикагрелора не увеличивало суммарный риск крупных кровотечений по сравнению с клопидогрелем, но было связано с большей частотой спонтанных крупных кровотечений (крупных кровотечений, не связанных с операцией шунтирования коронарных артерий), включая фатальные внутричерепные кровотечения [9]. Результаты исследования PLATO применительно к больным острым коронарным синдромом с подъемом сегмента ST касаются исключительно пациентов с планируемым первичным чрескожным коронарным вмешательством. Больные, получившие тромболитическую терапию в пределах 24 ч до рандомизации согласно протоколу исследования, не включались в исследование [9]. В итоге доказательств безопасного раннего применения тикагрелора у больных, получивших тромболитическую терапию, получено не было.

Европейские рекомендации по ведению больных острым коронарным синдромом с подъемом сегмента ST 2017 г. [1] предлагают использовать клопидогрел при тромболизисе, а переход на более мощные блокаторы Р2Y12 допускают только через 48 ч после введения тромболитического агента. Таким образом, для больных, подвергающихся фармакоинвазивному подходу, в действующих рекомендациях допускается переход от клопидогрела к прасугрелу или тикагрелору только после 48 ч от начала тромболизиса. Результаты исследования TREAT свидетельствуют о безопасности раннего (в пределах 24 4) применения тикагрелора у пациентов с острым коронарным синдромом с подъемом сегмента ST после тромболитической терапии $[4,10]$. В нашем исследовании мы ставили целью сравнить результаты повседневной клинической практики с результатами исследования TREAT у вышеназванной категории больных по показателям геморрагической безопасности раннего использования тикагрелора после тромболитической терапии (в первые 30 сут) без оценки его влияния на «большие» кардиоваскулярные события.

В результате анализа выборки пациентов можно отметить, что в нашем исследовании больные были более тяжелые: чаще встречались артериальная гипертензия, дислипидемия, генерализо- 
ванный атеросклероз, хроническая обструктивная болезнь легких, инфаркт миокарда в анамнезе, что говорит о недостаточной первичной профилактике сердечно-сосудистых заболеваний в регионе. Основным результатом нашей работы явилось отсутствие достоверных различий в частоте крупных кровотечений по критериям TIMI и BARC в сравнении с результатами исследования TREAT, что свидетельствует о безопасности раннего (в пределах 24 ч после выполнения тромболитической терапии) применения тикагрелора при фармакоинвазивном подходе в условиях реальной клинической практики.

Следует отметить, что в работе отражены краткосрочные результаты применения тикагрелора в составе двойной антиагрегантной терапии у больных острым коронарным синдромом с подъемом сегмента ST и фармакоинвазивной тактикой реперфузии миокарда. Долгосрочная сравнительная эффективность применения тикагрелора по сравнению с клопидогрелом в качестве второго антитромботического препарата у больных острым коронарным синдромом с подъемом сегмента ST еще не изучена.

\section{ЗАКЛЮЧЕНИЕ}

Достоверные различия в частоте крупных кровотечений по критериям TIMI и BARC между группами отсутствуют, что свидетельствует о безопасности раннего (в пределах 24 ч после выполнения тромболизиса) применения тикагрелора при фармакоинвазивном подходе в условиях реальной клинической практики.

\section{ИСТОЧНИК ФИНАНСИРОВАНИЯ}

Исследование и публикации статьи осуществлены на личные средства авторского коллектива.

\section{КОНФЛИКТ ИНТЕРЕСОВ}

Авторы данной статьи подтвердили отсутствие конфликта интересов, о котором необходимо сообщить.

\section{УЧАСТИЕ АВТОРОВ}

А.В. Бочаров - идея исследования, дизайн, набор материала, написание текста статьи, статистическая обработка, корректура; Д.В. Сидоров идея исследования, набор материала, написание текста статьи, корректура. Авторы внесли равноценный вклад в проведение поисково-аналитической работы и подготовку статьи, прочли и одобрили финальную версию до публикации.

\section{СПИСОК ЛИТЕРАТУРЫ}

1. Ibanez B, James S, Agewall S, et al. 2017 ESC Guidelines for the management of acute myocardial infarction in patients presenting with ST-segment elevation: the task force for the management of acute myocardial infarction in patients presenting with ST-segment elevation of the European Society of Cardiology (ESC). Eur Heart J. 2018;39:119-117. doi: 10.1093/eurheartj/ehx393.

2. Armstrong PW, Gershlick $A H$, Goldstein P, et al. Fibrinolysis or primary $\mathrm{PCl}$ in ST-segment elevation myocardial infarction. $N$ Engl J Med. 2013;368:1379-1387.

3. Mehran R, Rao SV, Bhatt DL, et al. Standardized bleeding definitions for cardiovascular clinical trials. A consensus report from the Bleeding Academic Research Consortium. Circulation.2011;123(23):2736-2747. doi: 10.1161/CIRCULATIONAHA.110.009449.

4. Berwanger O, Nicolau JC, Carvalho AC, et al. Ticagrelor versus clopidogrel after fibrinolytic therapy in patients with ST-elevation myocardial infarction: rationale and design of the TicagRElor in pAtients with ST elevation myocardial infarction treated with Thrombolysis (TREAT) trial. Am Heart J. 2018;202:89-96. doi: 10.1001/ jamacardio.2018.0612.

5. Hicks KA, Stockbridge NI, Targum SI, Temple R.J. Bleeding academic research consortium consensus report the Food and Drug Administration perspective. Circulation. 2011;123:2664-2665.

6. Rao AK, Pratt C, Berk A, et al. Thrombolysis in myocardial infarction (TIMI) trial-phase I: hemorragic manifestations and changes in plasma fibrinogen system and fibrinolytic system in patients treated with recombinant tissue plasminogen activator and streptokinase. JACC. 1988;11(1):1-11 doi: 10.1016/0735-1097(88)90158-1.

7. Chen ZM, Jiang LX, Chen YP, et al. Addition of clopidogrel to aspirin in 45,852 patients with acute myocardial infarction: randomised placebo-controlled trial. Lancet. 2005;366:1607-1621. doi: 10.1016/S0140-6736(05)67660-X.

8. Sabatine MS, Cannon CP, Gibson CM. et al. Addition of clopidogrel to aspirin and fibrinolytic therapy for myocardial infarction with ST-segment elevation. N Engl J Med. 2005;352:1179-1189. doi: 10.1056/NEJMoa050522.

9. Wallentin L, Becker RC, Budaj A, et al. Ticagrelor versus clopidogrel in patients with acute coronary syndromes. $N$ Engl J Med. 2009;361:1045-1057. doi: 10.1056/NEJMoa0904327.

10. Berwanger O, Lopes RD, Moia DF, et al. Ticagrelor versus clopidogrel in patients with STEMI treated with fibrinolysis. TREAT Trial. JACC. 2019;73(22):2819-2828. doi: 10.1016/j.jacc.2019.03.011.

\section{КОНТАКТНАЯ ИНФОРМАЦИЯ}

\section{Бочаров Александр Владимирович}

к.м.н., зав. отделением рентгенохирургических методов диагностики и лечения Костромской областной клинической больницы имени Королева Е.И.;

адрес: 156013, Кострома, пр. Мира, д. 114, e-mail: bocharovav@mail.ru, SPIN-код: 6073-1445, ORCID: http://orcid.org/0000-0002-6027-2898

\section{Сидоров Денис Владимирович}

врач-кардиолог палаты интенсивной терапии отделения кардиологии Регионального сосудистого Центра Костромской областной клинической больницы имени Королева Е.И.; e-mail: denis.sidorov1972@mail.ru 